\title{
Polysomnography in stable COPD under non-invasive ventilation to reduce patient-ventilator asynchrony and morning breathlessness
}

\author{
Dan Adler • Stephen Perrig • Hiromitsu Takahashi • \\ Fabrice Espa • Daniel Rodenstein - Jean Louis Pépin • \\ Jean-Paul Janssens
}

Received: 7 July 2011 /Revised: 7 July 2011 / Accepted: 11 October 2011 / Published online: 4 November 2011

(C) The Author(s) 2011. This article is published with open access at Springerlink.com

\begin{abstract}
Background Stable severe chronic obstructive pulmonary disease (COPD) patients with chronic hypercapnic respira-
\end{abstract}

Work performed at: Sleep laboratory, Department of Psychiatry, Geneva University Hospitals

The trial was registered at www.clinicaltrials.gov (Trial no. NCT01180439)

D. Adler $(\bowtie) \cdot$ H. Takahashi $\cdot$ J.-P. Janssens

Division of Pulmonary Diseases,

Geneva University Hospitals, Rue Gabrielle-Perret-Gentil 4,

1211 Geneva 14, Switzerland

email: dan.adler@hcuge.ch

H. Takahashi

email: Hiromitsu.Takahashi@hcuge.ch

J. -P. Janssens

e-mail: Jean-Paul.Janssens@hcuge.ch

D. Adler $\cdot$ S. Perrig $\cdot$ F. Espa

Sleep laboratory, Department of Psychiatry,

Geneva University Hospitals, 1211 Geneva 14, Switzerland

S. Perrig

e-mail: Stephen.Perrig@hcuge.ch

F. Espa

e-mail: Fabrice.Espa@hcuge.ch

D. Rodenstein

Division of Pulmonary Diseases, Clinique St Luc, Catholic University of Louvain, Brussels, Belgium

e-mail: Daniel.Rodenstein@uclouvain.be

\section{J. L. Pépin}

Sleep laboratory and HP2 Laboratory INSERM U 1042,

University Hospital, Grenoble, France

e-mail: JPepin@chu-grenoble.fr tory failure treated by nocturnal bi-level positive pressure non-invasive ventilation (NIV) may experience severe morning deventilation dyspnea. We hypothesised that in these patients, progressive hyperinflation, resulting from inappropriate ventilator settings, leads to patient-ventilator asynchrony (PVA) with a high rate of unrewarded inspiratory efforts and morning discomfort.

Methods Polysomnography (PSG), diaphragm electromyogram and transcutaneous capnography $\left(\mathrm{PtcCO}_{2}\right)$ under NIV during two consecutive nights using baseline ventilator settings on the first night, then, during the second night, adjustment of ventilator parameters under PSG with assessment of impact of settings changes on sleep, patient-ventilator synchronisation, morning arterial blood gases and morning dyspnea.

Results Eight patients $\left(61 \pm 8\right.$ years, $\mathrm{FEV}_{1} 30 \pm 8 \%$ predicted, residual volume $210 \pm 30 \%$ predicted) were included. In all patients, pressure support was decreased during setting adjustments, as well as tidal volume, while respiratory rate increased without any deleterious effect on nocturnal $\mathrm{PtcCO}_{2}$ or morning $\mathrm{PaCO}_{2}$. PVA index, initially high $(40 \pm 30 \%)$ during the baseline night, decreased significantly after adjusting ventilator settings ( $p=0.0009$ ), as well as subjective perception of PVA leaks, and morning dyspnea while quality of sleep improved. Conclusion The subgroup of COPD patients treated by home NIV, who present marked deventilation dyspnea and unrewarded efforts may benefit from adjustment of ventilator settings under PSG or polygraphy.

Keywords Non-invasive ventilation $\cdot$ COPD Patientventilator asynchrony
Abbreviations
COPD Chronic obstructive pulmonary disease
EEG Electroencephalogram 


\begin{tabular}{|c|c|}
\hline EMG & Electromyogram \\
\hline EPAP & Expiratory positive airway pressure \\
\hline $\mathrm{I} / \mathrm{E}$ ratio & Inspiratory/expiratory ratio \\
\hline IPAP & Inspiratory positive airway pressure \\
\hline $\mathrm{kHz}$ & Kilohertz \\
\hline $\mathrm{kPa}$ & Kilopascals \\
\hline MAI & Microarousal index \\
\hline NIV & Non-invasive ventilation \\
\hline $\mathrm{PaCO}_{2}$ & Arterial partial pressure of carbon dioxide \\
\hline PEEP & Positive end-expiratory pressure \\
\hline $\mathrm{PEEP}_{\mathrm{I}}$ & Intrinsic positive end-expiratory pressure \\
\hline PSG & Polysomnography \\
\hline $\mathrm{PtcCO}_{2}$ & $\begin{array}{l}\text { Transcutaneous measurement of arterial partial } \\
\text { pressure of carbon dioxide }\end{array}$ \\
\hline PVA & Patient-ventilator asynchrony \\
\hline RR & Respiratory rate \\
\hline SE & Sleep efficiency \\
\hline $\mathrm{SpO}_{2}$ & $\begin{array}{l}\text { Oxygen saturation of Haemoglobin measured by } \\
\text { pulsoximetry }\end{array}$ \\
\hline $\mathrm{TI}_{\mathrm{MAX}}$ & Maximal inspiratory time \\
\hline TST & Total sleep time \\
\hline VE & Minute ventilation \\
\hline $\mathrm{V}_{\mathrm{T}}$ & Tidal volume \\
\hline WASO & Wake after sleep onset \\
\hline
\end{tabular}

\section{Introduction}

Despite the lack of evidence to support its use in chronic obstructive pulmonary disease (COPD), noninvasive ventilation (NIV) is widely prescribed in this indication in Europe [1]. Although impact on survival remains controversial [2-4], most authors will agree that there appears to be a group of COPD patients who clearly benefit from NIV. Indeed, several studies have described improvements in health-related quality of life $[3,5,6]$, hospital admissions [7, 8], dyspnea [6] and quality of sleep [5].

Recent reviews have stressed the importance of identifying abnormal events occurring under NIV, and adjusting ventilator settings accordingly [9]. For instance, it is now established that patient-ventilator asynchrony (PVA) is frequent in patients undergoing chronic NIV who are considered effectively treated [10, 11]. PVA has a negative impact on quality of sleep and potentially on treatment efficacy [10]. Monitoring pulse oximetry $\left(\mathrm{SpO}_{2}\right)$ and transcutaneous capnography $\left(\mathrm{PtcCO}_{2}\right)$ alone do not explore this aspect of therapy adequately. Thus, in selected cases, polygraphy or polysomnography (PSG) might be ideal monitoring tools in addition to oxy-capnography for patients with home ventilation [12].
Among severe COPD under home NIV, patients are occasionally burdened by a severe dyspnea when interrupting their treatment after a night of NIV. We hypothesised that in these patients, inappropriate ventilator settings may lead to dynamic hyperinflation, increased intrinsic PEEP, resulting in unrewarded inspiratory efforts $[13,14]$ and morning discomfort when interrupting NIV [15]. We surmised that adjusting ventilator settings accordingly, during PSG under NIV, might improve quality of sleep, patient-ventilator synchronisation and morning dyspnea ('deventilation dyspnea').

\section{Materials and methods}

Patients

Eligible patients fulfilled the following inclusion criteria: (1) Severe COPD according to GOLD guidelines [16], (2) home NIV initiated according to prevailing recommendations [17], (3) stable clinical condition defined as absence of exacerbation and of modifications of ventilator settings in the month preceding the study, (4) compliance to NIV of more than $4 \mathrm{~h} /$ day assessed by ventilator software, (5) presence of deventilation dyspnea defined as severe dyspnea occurring immediately after interruption of non-invasive ventilation and preventing the patient from getting out of bed and carrying out usual daily activities for more than $30 \mathrm{~min}$ after one night of NIV. Severe morning dyspnea was assessed by a chest therapist using a modified Borg scale. All patients with morning dyspnea score $>4$ were proposed to enter the study. Exclusion criteria were: (1) use of NIV in an acute exacerbation of COPD for hypercapnic ventilatory failure, (2) association of COPD with restrictive thoracic disorders (i.e. morbid obesity, cyphoscoliosis, neuromuscular disease, sequelae of tuberculosis), and (3) patients under 18 years old or not able to give informed consent.

\section{Measurements}

\section{Polysomnography}

Conventional polysomnography with patient under NIV included: standard electroencephalography (seven electrodes, $\mathrm{F}_{4}-\mathrm{F}_{3}, \mathrm{O}_{1}-\mathrm{O}_{2}, \mathrm{C}_{3}-\mathrm{C}_{4}, \mathrm{C}_{\mathrm{z}}$ ), left and right electrooculography, submental electromyography (EMG), measurement of airflow using a pneumotachograph, body position, thoracic and abdominal movements (Remlogic 1.1, Embla, Netherlands) and video recording. $\mathrm{SpO}_{2}$ was measured continuously with a pulse oximeter and a finger probe. $\mathrm{PtcCO}_{2}$ measurements were performed using a 
transcutaneous capnograph with an ear probe heated at $43^{\circ}$ C (Tosca 500, Radiometer, Switzerland). Sleep was scored according to standard criteria using 30 -s epochs [18]. The investigator scoring the sleep study was blinded to the ventilator settings and subjective evaluation. The following sleep parameters were quantified: total sleep time (TST), sleep efficiency (SE-TST/total recording time $\times$ 100), percentage of each sleep stage, wake after sleep onset (WASO) and sleep latency. As indices of sleep fragmentation, we considered the index of micro-arousals (MAI). MAI were defined as a return to alpha or fast frequency, well-differentiated from the background EEG activity lasting $>1.5 \mathrm{~s}$.

\section{Diaphragm EMG}

Surface diaphragm EMG was recorded using silver electrodes in all subjects only to monitor inspiratory effort [19] and facilitate detection of ineffective inspiratory efforts. The electrodes were placed in the right and left anterior axillary line in the seventh intercostal space with a horizontal distance of $2 \mathrm{~cm}$. Diaphragmatic EMG was sampled at $0.2 \mathrm{kHz}$, bandpass-filtered between 10 and $70 \mathrm{~Hz}$ [20] and recorded with all other parameters on the Embla recording system.

\section{Patient-ventilator asynchrony}

Patterns of patient-ventilator asynchrony included ineffective triggering (unrewarded inspiratory efforts), double-triggering and auto-triggering, as defined by Thille et al. [13]. Unrewarded inspiratory efforts were identified as the occurrence of a definite diaphragmatic EMG signal, and/or presence of inspiratory thoracoabdominal movements on strain gauges without subsequent pressurisation by the ventilator. Auto-triggering was defined as a cycle delivered by the ventilator and not triggered by the patient. An unrewarded effort index was calculated as follows: [number of desynchronized cycles/ total respiratory rate (i.e. cycles supported by the ventilator plus unrewarded efforts) $] \times 100$ (expressed as a percentage) [21]. Only epochs (3 min.) with an unrewarded effort index above $10 \%$ were scored as periods with asynchrony based on a study by Vittaca and al. [22]. PVA index was calculated as the ratio of total sleep time spent with unrewarded efforts on TST [10].

\section{Ventilator built-in software}

Compliance, estimated tidal volume $\left(\mathrm{V}_{\mathrm{T}}\right)$, minute ventilation (VE), respiratory rate (RR), leaks and percent (\%) of spontaneous inspirations were downloaded after both nights from built-in software of bi-level ventilators
(ResScan software, version 1.3, ResMed, Sydney, Australia). Estimation of leaks and $V_{T}$ by ventilator software of VPAP III and VPAP IV ventilators (ResMed, Sydney, Australia) has been shown to be reliable in two recent independent studies [23, 24].

\section{Questionnaires}

After both nights, to evaluate patient comfort and patients' perception of patient-ventilator synchronisation, airflow, leaks and noise of ventilator, an eight-item visual analogue scale (VAS) was administered the morning following each sleep study [25]. Higher values indicate better comfort. Patients were also asked to quantify their dyspnea on a visual analogue scale while withdrawing from pressure support in the morning (10 worst dyspnea ever experienced in the morning, $0-$ no dyspnea at all).

\section{Study protocol}

Patients were admitted to the sleep laboratory for two consecutive nights. On the first night, ventilator settings were those normally used by the patient, thus eliminating the need of an accommodation night. This first night aimed to detect and quantify PVA in highly symptomatic COPD patients on their usual NIV settings. In our institution, ventilation settings are adjusted by chest therapists, under the supervision of the attending pulmonary physician, aiming at patient comfort and optimal control of daytime and nocturnal $\mathrm{SpO}_{2}$ and $\mathrm{PtcCO}_{2}$. On the second night, the therapeutic target was to reduce sleep-disordered breathing and patientventilator asynchrony. The investigators adjusted ventilator settings using polysomnography and monitoring of $\mathrm{SpO}_{2} / \mathrm{PtcCO}_{2}$.

Our approach was as follows: in case of unrewarded inspiratory efforts, we first reduced pressure support, then, if necessary, we increased expiratory positive airway pressure (EPAP) [15] and set expiratory trigger at a higher percentage of peak inspiratory flow to avoid delayed cycling [26, 27] under close monitoring of $\mathrm{PtcCO}_{2}$. When time to peak pressure (pressurisation time) was set at $100 \mathrm{msec}$, we increased it by 50 $100 \mathrm{msec}$. Back-up respiratory rate was increased if unrewarded inspiratory efforts persisted. Maximal inspiratory time $\left(\mathrm{TI}_{\mathrm{MAX}}\right)$ was calculated in order to maintain a physiological I/E ratio for COPD patients between 1:2.5 and $1: 3$.

If auto-triggering was identified, mask fit was adapted to prevent air leaks and inspiratory trigger sensitivity was reduced [28]. Inspiratory time $\left(\mathrm{TI}_{\mathrm{MIN}}\right)$ was increased if double triggering was frequent [13]. Special attention was 
given to mask leaks in order to limit their impact on patient-ventilator asynchrony.

\section{Statistical analysis}

Statistical testing was performed using Prism4 software (GraphPad, San Diego, CA, USA). When data were normally distributed (Schapiro-Wilk test), results were expressed as mean \pm SD. All variables between the two nights of the study protocol were compared using a paired $t$ test. Differences were considered significant when probability of a type I error was $<0.05$.

The study protocol was approved by the Ethics Committee for Medical Research of Geneva University Hospital and written informed consent was obtained from all patients. The trial was registered at www.clinicaltrials.gov (Trial No. NCT01180439)

\section{Results}

The study flow chart is depicted in Fig. 1. Among severe COPD patients treated by our outpatients clinic, $9 /$ 32 (28\%) exhibited 'deventilation dyspnea' and fulfilled inclusion criteria. We included eight consecutive COPD patients (aged 61 \pm 8.3 years, three males, five females, on NIV for $14.3 \pm 12.5$ months), admitted for a scheduled routine control of their nocturnal ventilation $(n=4$ on VPAP ST III, $n=4$ on VPAP IV bi-level ventilators; ResMed, Sydney, Australia) between October 2009 and
March 2010. One patient declined. Patients' main characteristics are shown in Table 1. All patients used their ventilator more than $4 \mathrm{~h}$ per night (Mean \pm SD9:06 \pm 3:20 hours) and suffered from severe morning dyspnea after interrupting their NIV (referred to as 'deventilation dyspnea').

Ventilator settings at baseline and adjustments under PSG

Baseline ventilator settings and settings after adjustment under PSG are shown in Table 2. Seven patients used full-face masks and one patient used a nasal interface. The major change performed in order to decrease unrewarded inspiratory efforts detected on PSG, was a decrease in pressure support in all cases ([IPAP-EPAP] baseline, $13.6 \pm 1.8 \mathrm{~cm} \mathrm{H}_{2} \mathrm{O}$; adjusted, $10.3 \pm 1.7 \mathrm{~cm} \mathrm{H}_{2} \mathrm{O}$; $p=.0005$ ). In seven cases, IPAP was reduced by $1-5 \mathrm{~cm}$ $\mathrm{H}_{2} \mathrm{O}$. In four cases, EPAP was also increased by $1-4 \mathrm{~cm}$ $\mathrm{H}_{2} \mathrm{O}$. Back-up rate was increased in four cases. Time to peak was slightly increased in all cases by $50-100 \mathrm{msec}$. $\mathrm{TI}_{\mathrm{MAX}}$ was adjusted to obtain a $\mathrm{I} / \mathrm{E}$ ratio between 1:2.5 and $1: 3$.

Sleep structure and respiratory events under NIV

Unrewarded inspiratory efforts were the most prevalent patient-ventilator asynchrony. PVA index was reduced after ventilator adjustment from $40.5 \pm 31.0$ to $6.7 \pm$ $7.3 \%, p=0.009$ (Fig. 2). Neither double triggering nor auto-triggering were identified during both nights. Fig-

Fig. 1 Study flow chart

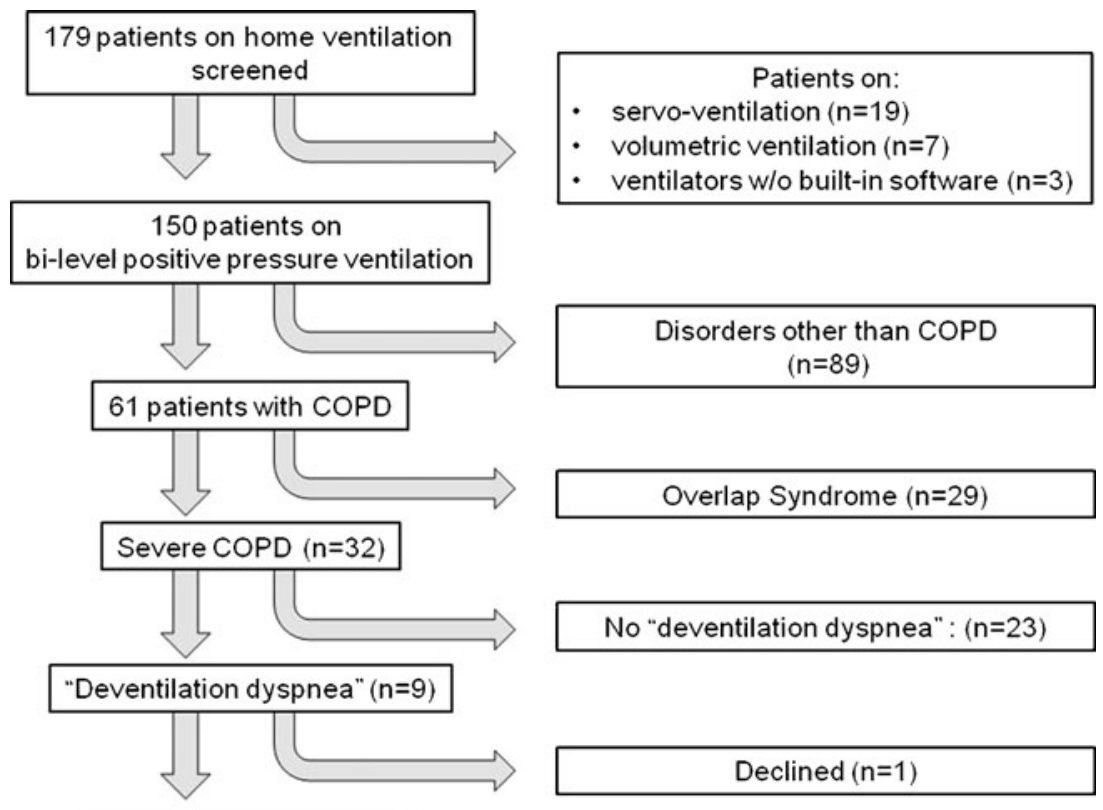

Patients included $(n=8)$ 
Table 1 Patients main characteristics

\begin{tabular}{|c|c|c|c|c|c|c|}
\hline Patients & Age & Gender & Ventilated for (months) & $\mathrm{FEV}_{1}(\%$ predicted $)$ & TLC (\% predicted) & $\mathrm{RV}$ (\% predicted) \\
\hline 1 & 56 & M & 39 & 25 & 120 & 240 \\
\hline 2 & 62 & M & 4 & 21 & 124 & 217 \\
\hline 3 & 58 & $\mathrm{~F}$ & 3 & 30 & 130 & 231 \\
\hline 4 & 65 & $\mathrm{~F}$ & 3 & 23 & 129 & 222 \\
\hline 5 & 52 & M & 10 & 28 & 118 & 213 \\
\hline 6 & 79 & $\mathrm{~F}$ & 14 & 39 & 154 & 228 \\
\hline 7 & 62 & $\mathrm{~F}$ & 17 & 30 & 111 & 185 \\
\hline 8 & 55 & $\mathrm{~F}$ & 24 & 47 & 108 & 147 \\
\hline Mean & 61 & & 14.3 & 30.4 & 124.2 & 210.4 \\
\hline SD & 8 & & 12.5 & 8.7 & 14.3 & 30.4 \\
\hline
\end{tabular}

ure 3 shows a representative correction of unrewarded inspiratory efforts by NIV adjustment under sleep polygraphy.

Neither total sleep time (TST $445 \pm 126$ vs. $448 \pm$ $96 \mathrm{~min}$ ), wake after sleep onset (WASO $41 \pm 21$ vs. $41 \pm$ $24 \mathrm{~min}$ ), nor micro arousal index (MAI $18 \pm 9$ vs. $20 \pm 12 \mathrm{~h}$ ) were altered by changes in ventilator settings.
Subjective assessment

The major impact of ventilator adjustment was a marked decrease in morning dyspnea measured by an adapted Borg Scale (values from 0 to 10 , increasing values mean increasing dyspnea), for all subjects as shown in Fig. 3 (5.8 \pm 2.5 vs. $2.3 \pm 1.6, p=0.006)$.

Table 2 Ventilator settings before and after adjustment under PSG

\begin{tabular}{|c|c|c|c|c|c|c|}
\hline Patients & IPAP $\left(\mathrm{cmH}_{2} \mathrm{O}\right)$ & EPAP $\left(\mathrm{cmH}_{2} \mathrm{O}\right)$ & Pressure support $\left(\mathrm{cmH}_{2} \mathrm{O}\right)$ & Back-up rate (/min) & Time to peak (ms) & $\mathrm{TI}_{\mathrm{MAX}}(\mathrm{s})$ \\
\hline \multicolumn{7}{|c|}{ Initial ventilator settings } \\
\hline 1 & 22 & 5 & 17 & 13 & 100 & 1.2 \\
\hline 2 & 18 & 6 & 12 & 14 & 100 & 1.2 \\
\hline 3 & 18 & 6 & 12 & 14 & 100 & 1.2 \\
\hline 4 & 19 & 5 & 14 & 14 & 100 & 1.2 \\
\hline 5 & 16 & 4 & 12 & 12 & 100 & 1.5 \\
\hline 6 & 19 & 4 & 15 & 14 & 100 & 1.4 \\
\hline 7 & 18 & 5 & 13 & 14 & 100 & 1.1 \\
\hline 8 & 22 & 8 & 14 & 14 & 100 & 1.3 \\
\hline Mean & 19 & 5.4 & 13.6 & 13.6 & 100 & 1.26 \\
\hline SD & 2.1 & 1.3 & 1.8 & 0.7 & 0 & 0.13 \\
\hline \multicolumn{7}{|c|}{ Adjusted ventilator settings } \\
\hline 1 & 17 & 5 & 12 & 13 & 200 & 1.2 \\
\hline 2 & 17 & 6 & 12 & 14 & 200 & 1.1 \\
\hline 3 & 14 & 5.4 & 8.6 & 14 & 150 & 1.3 \\
\hline 4 & 15 & 6 & 9 & 19 & 150 & 1.1 \\
\hline 5 & 14 & 6 & 8 & 16 & 150 & 1.1 \\
\hline 6 & 16 & 4 & 12 & 14 & 150 & 1.4 \\
\hline 7 & 18.6 & 9 & 9.6 & 19 & 200 & 1.1 \\
\hline 8 & 20 & 9 & 11 & 17 & 200 & 1.2 \\
\hline Mean & $16.5^{*}$ & $6.3 * * *$ & $10.3^{* *}$ & $15.8 * * *$ & $175^{* *}$ & $1.19 * * *$ \\
\hline SD & 2.1 & 1.8 & 1.7 & 2.4 & 26.7 & 0.11 \\
\hline
\end{tabular}

$F E V_{l}$ Forced expiratory volume in $1 \mathrm{~s}, T L C$ total lung capacity, $R V$ residual volume, IPAP inspiratory positive airway pressure, $E P A P$ expiratory positive airway pressure, $R R$ respiratory rate, $T I_{M A X}$ maximal inspiratory time

${ }^{*} p=0.04 ;{ }^{* *} p<0.0005 ;{ }^{* *} p=\mathrm{NS}, P$ values for paired $t$ tests comparing baseline vs. adjusted ventilator settings 


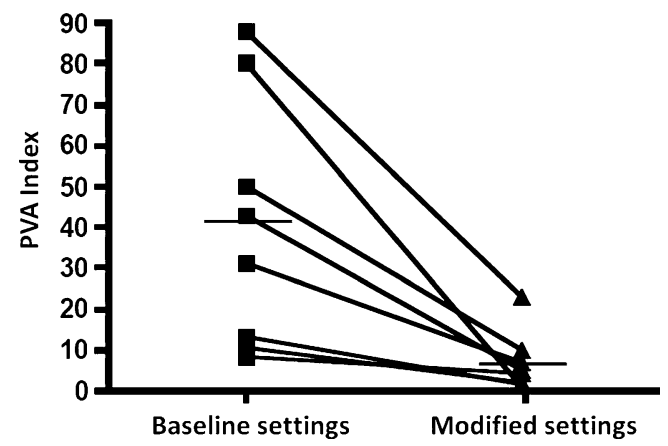

Fig. 2 Patient-ventilator asynchrony index (PVA index: total time spent with unrewarded efforts/total sleep time) for each patient before and after NIV adjustment with polysomnography

The eigh-point VAS also showed significant improvements for perception of patient-ventilator synchronisation $(p=0.04)$, perception of leaks $(p=0.04)$ and overall quality of sleep $(p=0.01)$ (Fig. 4). None of the VAS scales decreased (i.e. worsened).
Data provided by ventilator built-in software

Changes in estimated tidal volume $\left(\mathrm{V}_{\mathrm{T}}\right)$, total ventilation (VE), spontaneous respiratory rate (RR) and percentage of inspiratory cycles triggered by the patient are reported in Table 3. Ventilation pattern changed after adjusting ventilator parameters, with a significant decrease in $\mathrm{V}_{\mathrm{T}}$, and increase in spontaneous RR. The increase in percentage of inspiratory cycles triggered by the patient most probably reflects a better patient-ventilator synchronisation and improved detection of inspiratory efforts by the ventilator [12]. Average leaks were low during both recordings for all patients with a nonsignificant trend for lower leaks ( $95 \%$ percentile) after adjusting ventilator settings $(28 \pm 25$ vs. $17 \pm 19 \mathrm{~L} / \mathrm{min}, p=0.057)$.

Nocturnal $\mathrm{SpO}_{2}$ and nocturnal/daytime $\mathrm{CO}_{2}$ values

Mean nocturnal $\mathrm{SpO}_{2}$ was $92 \pm 3 \%$ on the first night and $91 \pm$ $2 \%$ after adjustment of settings under PSG ( $p$ value NS). Oxygen desaturation index was low and did not differ
Fig. 3 a Example of unrewarded inspiratory efforts with initial ventilator settings. From top to bottom - flow, pressure, diaphragm EMG, thoracic and abdominal belts. This 60-s epoch shows major patient-ventilator asynchrony. Unrewarded efforts can easily be identified by comparing the EMG trace or that of the abdominal and thoracic belts with the flow or pressure traces. The patients' inspiratory efforts do not trigger the ventilator which is on its back-up rate. b Correction of patient-ventilator asynchrony by adjustment of ventilator settings with polysomnography (60-s epoch). Flow, pressure, diaphragm EMG and abdominal and thoracic belts are perfectly synchronised. All inspiratory efforts trigger the ventilator resulting in an increased respiratory rate a

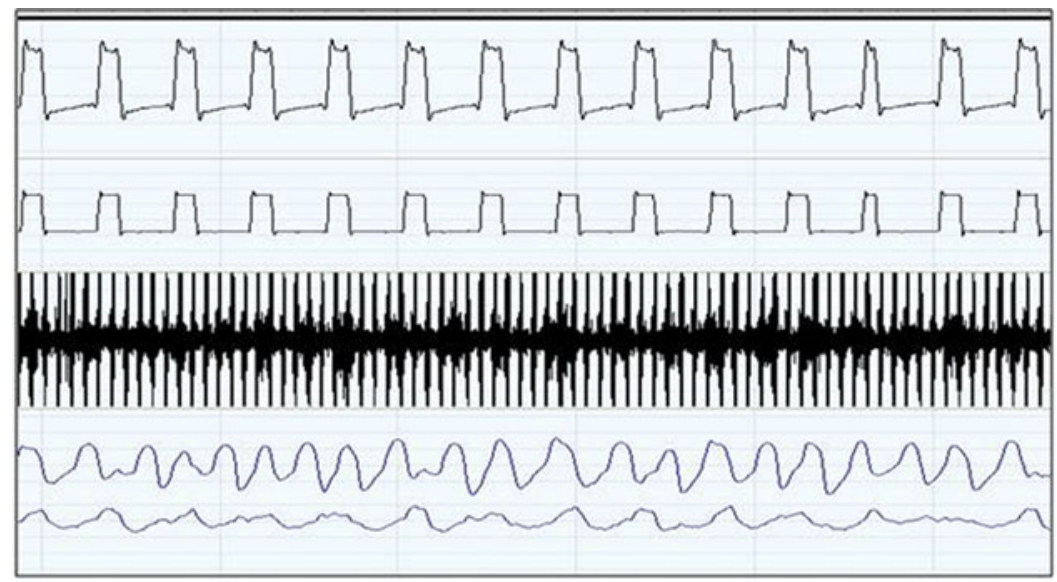

b

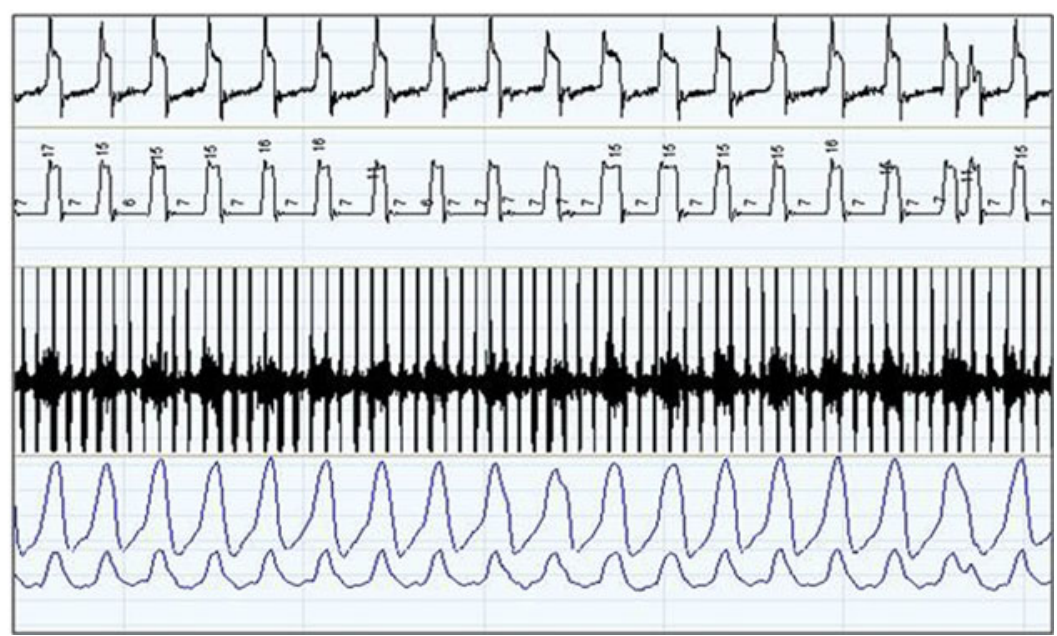


Fig. 4 Correction of deventilation dyspnea by adjusting ventilator settings with polysomnography is illustrated for each individual patient on a modified Borg scale (a, upper left). On a 0-10 visual analogue scale, subjective assessment of ventilator synchronisation (b), leaks (c) and overall quality of sleep (d) all improved a) Morning Dyspnea

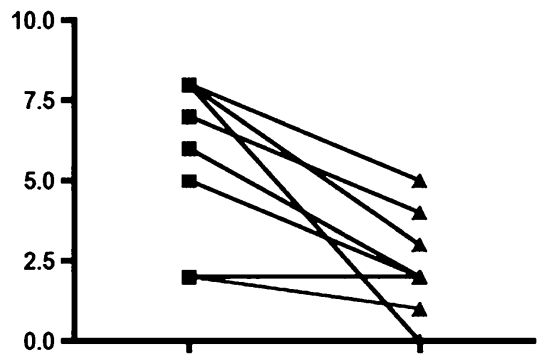

c) Perception of leaks

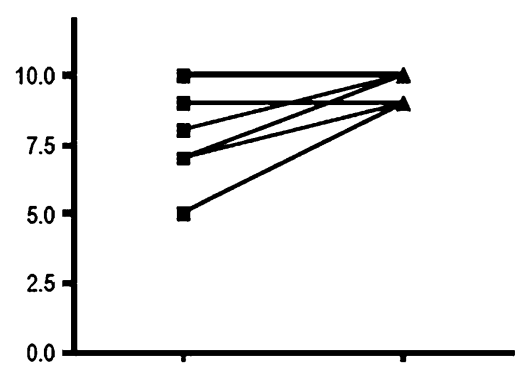

b) Ventilator synchronisation

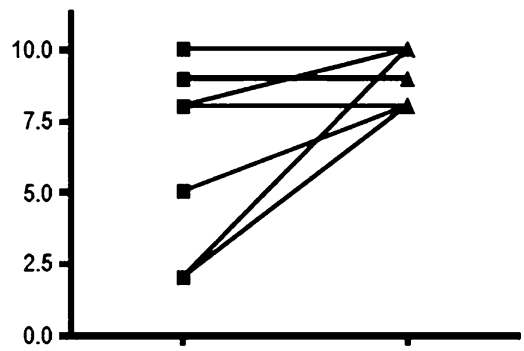

d) Overall quality of sleep

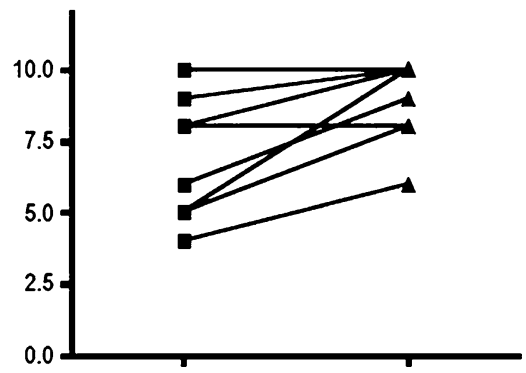

Table 3 Data downloaded from ventilator software, transcutaneous capnography and arterial blood gases: baseline values and values after adjusting ventilator parameters

\begin{tabular}{|c|c|c|c|c|c|c|}
\hline Patients & $V_{\mathrm{T}}(\mathrm{ml})$ & $\mathrm{RR}(/ \min )$ & $\mathrm{VE}(1 / \min )$ & Percent (\%) of spontaneous inspirations & $\mathrm{PtcCO}_{2}(\mathrm{kPa})$ & $\mathrm{PaCO}_{2}(\mathrm{kPa})$ \\
\hline \multicolumn{7}{|c|}{ Initial ventilator settings } \\
\hline 1 & 850 & 16 & 13.8 & 52 & 7.7 & 6.5 \\
\hline 2 & 660 & 14 & 7.6 & 36 & 6.7 & 5.7 \\
\hline 3 & 410 & 17 & 6.3 & 9 & 6.9 & 7.6 \\
\hline 4 & 650 & 15 & 8.2 & 7 & 6.6 & 8.4 \\
\hline 5 & 650 & 12 & 10 & 31 & 9.6 & 10 \\
\hline 6 & 650 & 14 & 8 & 25 & 6.3 & 6.9 \\
\hline 7 & 350 & 21 & 10.8 & 90 & 8.9 & 8.4 \\
\hline 8 & 600 & 17 & 8.1 & 90 & 7.4 & 7.6 \\
\hline Mean & 603 & 15.8 & 9.1 & 43 & 7.5 & 7.6 \\
\hline SD & 157 & 2.7 & 2.4 & 33 & 1.2 & 1.3 \\
\hline \multicolumn{7}{|c|}{ Adjusted ventilator settings } \\
\hline 1 & 450 & 26 & 13.2 & 96 & 8.6 & 6 \\
\hline 2 & 380 & 18 & 7.3 & 86 & 6.8 & 5.8 \\
\hline 3 & 340 & 20 & 7 & 40 & 6.8 & 6.9 \\
\hline 4 & 480 & 21 & 6.2 & 63 & 6.8 & 7.9 \\
\hline 5 & 350 & 17 & 9.4 & 46 & 8.8 & 10.5 \\
\hline 6 & 500 & 18 & 7.8 & 85 & 6.4 & 6.5 \\
\hline 7 & 350 & 20 & 11 & 63 & 7.8 & 7.7 \\
\hline 8 & 600 & 17 & 8.1 & 40 & 6.4 & 7.1 \\
\hline Mean & $431 *$ & $19.6 * *$ & $8.8^{* * *}$ & $65 * * *$ & $7.3 * * *$ & $7.3 * * *$ \\
\hline SD & 93 & 3 & 2.3 & 22 & 1 & 1.5 \\
\hline
\end{tabular}

$V_{T}$ Tidal volume, $R R$ respiratory rate, $V E$ minute ventilation, $P t c C \mathrm{O}_{2}$ transcutaneous $\mathrm{CO}_{2}, \mathrm{PaCO}_{2}$ morning arterial $\mathrm{CO}_{2}$ under NIV ${ }^{*} p=0.01 ; * *^{*}=0.02 ; * * * p=\mathrm{NS}, P$ values for paired $t$ tests comparing baseline vs. adjusted ventilator settings 
between both nights $(3.8 \pm 6.0$ vs. $3.5 \pm 2.9, p$ value NS). Despite a significant reduction in pressure support after adjusting ventilator settings, mean $\mathrm{PtcCO}_{2}$ decreased slightly although not significantly $(7.5 \pm 1.2$ vs. $7.3 \pm 1.0 \mathrm{kPa})$. Average morning $\mathrm{PaCO}_{2}$ under NIV also decreased after adjustment of ventilator settings $(7.6 \pm 1.3$ vs. $7.3 \pm 1.5 \mathrm{kPa}$, $p=0.057$ ).

\section{Discussion}

Among severe COPD patients treated at home by NIV, nearly one third complained of 'deventilation dyspnea'. Our study shows in this population that a very high rate of patient-ventilator asynchrony may occur (mainly unrewarded inspiratory efforts) and remain undetected without PSG. Adjusting ventilator settings after monitoring of nocturnal NIV by PSG can: (1) improve markedly patient-ventilator synchronisation, particularly triggering of ventilator; (2) improve patient comfort; (3) lead to a marked decrease in morning 'deventilation dyspnea'; (4) change ventilation pattern to a more physiological mode for severe COPD, i.e. increase spontaneous respiratory rate with a slight decrease in tidal volume, without any deterioration of $\mathrm{PaCO}_{2}$ or $\mathrm{PtcCO}_{2}$.

The observation that a high rate of unrewarded efforts occurred and was undetected in these patients confirms previous observations showing a high rate of patientventilator asynchrony in stable patients under NIV, most often not reported by the patient $[10,11,14]$. Although systematic polysomnography is clearly not warranted in stable patients under NIV, in these eight cases, PSG was indicated by the importance of morning deventilation dyspnea and the modest impact of NIV on $\mathrm{PtcCO}_{2}$ [12]. Adjusting ventilator settings had a nonsignificant impact on arterial blood gases, but a marked effect on patient comfort, patient-ventilator synchrony and morning dyspnea. Whether these changes are relevant as major endpoints of NIV is debatable, but it seems reasonable to assume that these improvements may have an impact on quality of life and acceptance of treatment. Indeed, morning deventilation dyspnea is a source of important discomfort and distress in these patients.

It may be objected that correction of alveolar hypoventilation in our patients was insufficient. Indeed, both morning arterial blood gases and nocturnal capnography show a residual hypercapnia. Recent publications by Windisch et al. suggest that normalising $\mathrm{PaCO}_{2}$ under NIV may be an important goal, through the use of high levels of pressure support and high back-up respiratory rates: this approach was shown to be feasible, to improve daytime $\mathrm{PaCO}_{2}$, daytime dyspnea, HRQL and $\mathrm{FEV}_{1}[6,29,30]$. The use of high-intensity ventilation and its application in clinical practice still remains a subject of debate. Indeed, several publications on long-term NIV in COPD have used much lower insufflation pressures [2-5]. In our centre, our aim is to obtain the best compromise between reduction of $\mathrm{PaCO}_{2} /$ $\mathrm{PtcCO}_{2}$, induced leaks and patient tolerance. Thus, for all patients, initial settings of pressure support were as high as tolerated. Residual hypercapnia in very severe COPD treated by NIV is frequently reported. All patients included in our study had severe COPD according to GOLD criteria, had had several exacerbations with acute hypercapnic respiratory failure, and had a baseline $\mathrm{PaCO}_{2}>7.3 \mathrm{kPa}$.

The mechanisms suggested for the relationship between nocturnal PSG findings and 'deventilation dyspnea' are hypothetical and probably differ according to the underlying pathology. In selected subjects with severe COPD and static hyperinflation, excessive pressure support might lead to dynamic hyperinflation and increased PEEPi [31] which are major determinants of unrewarded efforts [21]. Dynamic hyperinflation has been shown to correlate strongly with exercise-induced dyspnea in COPD [32] and may explain the importance of 'deventilation dyspnea'. Therefore, patientventilator asynchrony may, in these subjects, be a marker of inappropriate ventilator settings as demonstrated in the acute setting [26]. Arguments in favour of such a mechanism arein the patients studied - severity of bronchial obstruction and the presence of static air trapping which may curtail the patients' ability to take in large tidal volumes on NIV without developing dynamic hyperinflation (Table 1). However, the setting of this study did not allow performing serial measurements of inspiratory capacity after cessation of NIV; furthermore, PEEP $_{\mathrm{I}}$ could not be estimated non-invasively.

NIV can thus be considered as a two-edged sword in severe COPD. On one hand, Diaz et al. have shown that efficient NIV may decrease residual volume, functional residual capacity and total lung capacity when compared to sham NIV [33]. On the other hand, inappropriately high pressure support may have in certain patients a negative impact on lung mechanics and increase unrewarded efforts and patient-ventilator asynchrony [26]. Finding the best compromise between too high pressure support (with patient-ventilator asynchrony), efficacy of ventilation and patient comfort under monitoring by polygraphy or PSG might be a relevant clinical target.

Limitations of this study are its non-blinded and nonrandomised design. The sequence of night sleep studies were dictated by necessity of a pragmatic step-by-step assessment: the first night to identify patient-ventilator asynchrony during sleep, the second to correct them under appropriate monitoring. As patients were long-time NIV users, the first night effect on sleep quality can be considered as negligible. Moreover, ineffective efforts are objective measurements not influenced by randomization. Thus, we believe that the initial PSG reliably reflected patient-ventilator interactions at home. The advantage of our study design was to validate an effective and 
feasible procedure for NIV adjustment in clinical practice for COPD complaining from 'deventilation dyspnea'. The sample size is another limitation of our study. This may have precluded the demonstration of significant improvements in objective sleep quality which is suggested by nearly significant increases in sleep efficiency $(69 \pm 18 \%$ vs. $76 \pm 13 \%$, n.s. $)$ and slow wave and REM sleep ( $\% \mathrm{~N} 3+\mathrm{REM} 29 \pm 12 \%$ vs. $38 \pm 14 \%$, n.s.).

In summary, this study shows that in a selected group of stable severe COPD with hyperinflation treated by NIV, patient-ventilator asynchrony and ineffective inspiratory efforts are frequent, most probably increasing work of breathing and decreasing the efficacy of ventilation; this observation may explain the occurrence of morning deventilation dyspnea. After a diagnostic PSG or polygraphy, adjusting ventilator settings may lead to a significant decrease of ineffective inspiratory efforts and a significant improvement of patient comfort during and after NIV.

Acknowledgements The authors wish to thank the Pulmonary League of Geneva (Ligue Pulmonaire Genevoise: www.lpge.ch) for its financial support.

\section{Conflict of interest None.}

Open Access This article is distributed under the terms of the Creative Commons Attribution Noncommercial License which permits any noncommercial use, distribution, and reproduction in any medium, provided the original author(s) and source are credited.

\section{References}

1. Lloyd-Owen SJ, Donaldson GC, Ambrosino N, Escarabill J, Farre R, Fauroux B, Robert D, Schoenhofer B, Simonds AK, Wedzicha JA (2005) Patterns of home mechanical ventilation use in Europe: results from the Eurovent survey. Eur Respir J 25(6):1025-1031

2. Casanova C, Celli BR, Tost L, Soriano E, Abreu J, Velasco V, Santolaria F (2000) Long-term controlled trial of nocturnal nasal positive pressure ventilation in patients with severe COPD. Chest 118(6):1582-1590

3. Clini E, Sturani C, Rossi A, Viaggi S, Corrado A, Donner CF, Ambrosino N (2002) The Italian multicentre study on noninvasive ventilation in chronic obstructive pulmonary disease patients. Eur Respir J 20(3):529-538

4. McEvoy RD, Pierce RJ, Hillman D, Esterman A, Ellis EE, Catcheside PG, O’Donoghue FJ, Barnes DJ, Grunstein RR (2009) Nocturnal non-invasive nasal ventilation in stable hypercapnic COPD: a randomised controlled trial. Thorax 64(7):561-566

5. Meecham Jones DJ, Paul EA, Jones PW, Wedzicha JA (1995) Nasal pressure support ventilation plus oxygen compared with oxygen therapy alone in hypercapnic COPD. Am J Respir Crit Care Med 152(2):538-544

6. Dreher M, Storre JH, Schmoor C, Windisch W High-intensity versus low-intensity non-invasive ventilation in patients with stable hypercapnic COPD: a randomised crossover trial. Thorax 65 (4):303-308

7. Leger P, Bedicam JM, Cornette A, Reybet-Degat O, Langevin B, Polu JM, Jeannin L, Robert D (1994) Nasal intermittent positive pressure ventilation. Long-term follow-up in patients with severe chronic respiratory insufficiency. Chest 105(1):100-105
8. Janssens JP, Derivaz S, Breitenstein E, De Muralt B, Fitting JW, Chevrolet JC, Rochat T (2003) Changing patterns in long-term noninvasive ventilation: a 7 -year prospective study in the Geneva Lake area. Chest 123(1):67-79

9. Gonzalez-Bermejo J, Perrin C, Janssens JP, Pepin JL, Mroue G, Leger P, Langevin B, Rouault S, Rabec C, Rodenstein D (2010) Proposal for a systematic analysis of polygraphy or polysomnography for identifying and scoring abnormal events occurring during noninvasive ventilation. Thorax. doi:10.1136/thx.2010.142653

10. Guo YF, Sforza E, Janssens JP (2007) Respiratory patterns during sleep in obesity-hypoventilation patients treated with nocturnal pressure support: a preliminary report. Chest 131(4):1090-1099

11. Fanfulla F, Taurino AE, Lupo ND, Trentin R, D'Ambrosio C, Nava S (2007) Effect of sleep on patient/ventilator asynchrony in patients undergoing chronic non-invasive mechanical ventilation. Respir Med 101(8):1702-1707

12. Janssens JP, Borel JC, Pepin JL (2011) Nocturnal monitoring of home non-invasive ventilation: the contribution of simple tools such as pulse oximetry, capnography, built-in ventilator software and autonomic markers of sleep fragmentation. Thorax 66(5):438-445

13. Thille AW, Rodriguez P, Cabello B, Lellouche F, Brochard L (2006) Patient-ventilator asynchrony during assisted mechanical ventilation. Intensive Care Med 32(10):1515-1522

14. Vitacca M, Nava S, Confalonieri M, Bianchi L, Porta R, Clini E, Ambrosino N (2000) The appropriate setting of noninvasive pressure support ventilation in stable COPD patients. Chest 118 (5):1286-1293

15. Jolliet P, Tassaux D (2006) Clinical review: patient-ventilator interaction in chronic obstructive pulmonary disease. Crit Care 10 (6): 236

16. Rabe KF, Hurd S, Anzueto A, Barnes PJ, Buist SA, Calverley $\mathrm{P}$, Fukuchi Y, Jenkins C, Rodriguez-Roisin R, van Weel C, Zielinski J (2007) Global strategy for the diagnosis, management, and prevention of chronic obstructive pulmonary disease: GOLD executive summary. Am J Respir Crit Care Med 176 (6):532-555

17. (1999) Clinical indications for noninvasive positive pressure ventilation in chronic respiratory failure due to restrictive lung disease, COPD, and nocturnal hypoventilation- $\mathrm{a}$ consensus conference report. Chest 116(2):521-534

18. (1999) Sleep-related breathing disorders in adults: recommendations for syndrome definition and measurement techniques in clinical research. The Report of an American Academy of Sleep Medicine Task Force. Sleep 22(5):667-689

19. Stoohs RA, Blum HC, Knaack L, Butsch-von-der-Heydt B, Guilleminault C (2005) Comparison of pleural pressure and transcutaneous diaphragmatic electromyogram in obstructive sleep apnea syndrome. Sleep 28(3):321-329

20. Delhez L (1968) Electromyography of the diaphragm in man. Electromyogr 8(3):253-255

21. Chao DC, Scheinhorn DJ, Stearn-Hassenpflug M (1997) Patientventilator trigger asynchrony in prolonged mechanical ventilation. Chest 112(6): 1592-1599

22. Vitacca M, Bianchi L, Zanotti E, Vianello A, Barbano L, Porta R, Clini E (2004) Assessment of physiologic variables and subjective comfort under different levels of pressure support ventilation. Chest 126(3):851-859

23. Rabec C, Georges M, Kabeya NK, Baudouin N, Massin F, Reybet-Degat O, Camus P (2009) Evaluating noninvasive ventilation using a monitoring system coupled to a ventilator: a bench-to-bedside study. Eur Respir J 34(4):902-913

24. Contal O, Vignaux L, Combescure C, Pépin J-L, Jolliet P, Janssens J-P (2011) Performance of built-in software in home ventilators for assessment of leaks: a bench model study. Chest. doi:10.1378/chest.11-0485 
25. Janssens JP, Metzger M, Sforza E (2009) Impact of volume targeting on efficacy of bi-level non-invasive ventilation and sleep in obesity-hypoventilation. Respir Med 103(2):165-172

26. Thille AW, Cabello B, Galia F, Lyazidi A, Brochard L (2008) Reduction of patient-ventilator asynchrony by reducing tidal volume during pressure-support ventilation. Intensive Care Med 34(8):1477-1486

27. Tassaux D, Gainnier M, Battisti A, Jolliet P (2005) Impact of expiratory trigger setting on delayed cycling and inspiratory muscle workload. Am J Respir Crit Care Med 172(10):1283-1289

28. Mehta S, McCool FD, Hill NS (2001) Leak compensation in positive pressure ventilators: a lung model study. Eur Respir J 17(2):259-267

29. Windisch W, Kostic S, Dreher M, Virchow JC Jr, Sorichter S (2005) Outcome of patients with stable COPD receiving con- trolled noninvasive positive pressure ventilation aimed at a maximal reduction of $\mathrm{PaCO}$. Chest 128(2):657-662

30. Windisch W, Haenel M, Storre JH, Dreher M (2009) Highintensity non-invasive positive pressure ventilation for stable hypercapnic COPD. Int J Med Sci 6(2):72-76

31. Leung P, Jubran A, Tobin MJ (1997) Comparison of assisted ventilator modes on triggering, patient effort, and dyspnea. Am J Respir Crit Care Med 155(6):1940-1948

32. O'Donnell DE, Webb KA (1993) Exertional breathlessness in patients with chronic airflow limitation. The role of lung hyperinflation. Am Rev Respir Dis 148(5):1351-1357

33. Diaz O, Begin P, Torrealba B, Jover E, Lisboa C (2002) Effects of noninvasive ventilation on lung hyperinflation in stable hypercapnic COPD. Eur Respir J 20(6):1490-1498 